Fortnightly Review

\title{
Treatment of anxiety
}

\author{
Malcolm Lader
}

The anxiety disorders are common conditions-community surveys suggesting that at any one time about $3-5 \%$ of the adult population suffers generalised anxiety or panic disorder. However, many more suffer lesser degrees of anxiety, usually related to stresses in the environment, so that at least $15 \%$ of patients attending general practitioners' surgeries seek treatment for this unpleasant symptom.'

For many years the stock treatment for anxiety was an anxiolytic benzodiazepine, but misgivings over side effects and dependence potential have led many prescribers to lessen or eschew their use. Instead, a variety of treatments, drug and non-drug, are being tried. The purpose of this article is to review the present status of the treatment of anxiety, in as practical a way as possible, ${ }^{2}$ in line with previously published guidelines. $^{3}$

Box 1-Anxiety
disorders
- Generalised anxiety
disorder
- Panic disorder
- Agoraphobia
- Social phobia
- Simple phobia
- Post-traumatic stress
disorder
- Obsessive-compulsive
disorder

\section{The syndromes}

A long list of disorders (box 1) falls under the rubric of anxiety disorders. ${ }^{4} \mathrm{~A}$ few points are worth noting. Firstly, the diagnostic criteria for generalised anxiety disorders (GAD) emphasise that the worry about life circumstances produces unrealistic or excessive anxiety. This contrasts with stress related anxiety, in which the anxiety is proportional to the adverse life circumstances. In panic disorder, the panic attacks are unexpected-that is, not related to a phobic situation. In both generalised anxiety disorder and panic disorder, therefore, there is an element of inexplicability about the symptoms, but the symbolism of the anxiety provocation often becomes apparent in psychotherapy.

The treatment of the phobic states is primarily behavioural and the province of clinical psychologists, and obsessive-compulsive disorder sits uncomfortably among the anxiety disorders. The focus of this article will therefore be the treatment of generalised anxiety disorder and panic disorder, with an extension into stress related anxiety. Distinguishing between normal and clinical anxiety is not always easy, ${ }^{5}$ and patients seek and need treatment when their symptoms distress them or interfere with everyday functioning.

\section{Initial assessment}

Patients usually present first to their general practitioner, although a severe panic attack may lead the sufferer to rush to an accident and emergency department, fearing a heart attack. The general practitioner should first exclude a physical cause for the anxiety symptoms. Thyrotoxicosis is the commonest cause; others such as phaechromocytoma are textbook rarities. It is important not to "medicalise" the patient's anxiety

Summary points
- Anxiety disorders are common in primary
care and comprise several overlapping condi-
tions
- Generalised anxiety disorder and panic
disorder need careful assessment and then a well
chosen mix of general measures and sometimes
psychological or pharmacological treatments
Simple supportive strategies are adequate for
the milder degrees of disorder
- Several psychological techniques are effec-
tive but availability of specialised help is limited
- Drug treatment may be needed initially and
in the short term (benzodiazepines are appro-
priate) or later and in the long term (antidepres-
sants are appropriate)
- Specialist referral is needed for a minority
of patients-those who are severely ill, have
complications, or are refractory to treatment

by sending him or her for more and more esoteric (and expensive) investigations. The use of alcohol, beverages containing caffeine, and illicit drugs should also be asked about. Anyone taking more than, say, four cups of coffee or tea a day should be asked to try to lessen their intake. ${ }^{6}$ Anxious patients already taking a benzodiazepine will need special assessment for possible withdrawal and later reassessment.

Depression often coexists with anxiety and must be carefully sought by appropriate questioning. Differences in symptom patterns can be discerned and help the diagnosis (box 2), but in some patients symptoms are mixed. If depression is predominant or appreciable it should be treated; the anxiety usually lessens as a secondary response. Benzodiazepines are not useful antidepressants.?

\section{Management in primary care}

Simple explanation, support, and counselling are sufficient for most patients, especially those with understandable anxiety. Explanation of symptoms is essential, and most patients are reassured to be told that their headaches are due to tension and not a brain tumour or their palpitations to anxiety and not a heart attack. Bland, general reassurance is not sufficient and may well be misunderstood.

At this early stage in the illness, patients can be counselled in terms of their perception of anxiety and its meaning to them, viewing it as a potentially soluble 


\section{Box 2-Distinction between depression and anxiety \\ Features of anxiety \\ Inner tension \\ A feeling of impending doom \\ Worrying about trifles \\ Difficulty falling asleep \\ May lose appetite \\ Difficulty concentrating \\ due to distractability \\ Agitation \\ Autonomic symptoms \\ Features of depression \\ Permeating sadness \\ Pessimism \\ Self guilt \\ Disrupted sleep \\ Usually loses weight \\ Loss of libido \\ Insistent thoughts \\ impair concentration \\ Retardation or agitation \\ Self neglect \\ Hypochondriasis}

But distinction is not always easy

problem. They are usually prepared to take an active role in dealing with anxiety. Counselling can be nondirective or directive. In non-directive counselling the client controls the content of the sessions and the counsellor listens, tries to understand, asks appropriate questions, and generally responds in a warm supportive way. In directive counselling, specific sources of anxiety in the patient's circumstances are identified and the patient is encouraged to tackle these problems either directly or by making changes in lifestyle, personal relationships, or even occupation. Specific advice, or general help concerning problem identification and solving, may be given. Counselling should also include the provision or recommendation of self help material such as booklets and audio or video tapes: many are available. ${ }^{89}$ The lessons learnt through these media should be discussed in a counselling session.

The availability of counselling will depend on local resources. Some general practitioners may be prepared to devote some time to learning basic counselling techniques and then to devote four or five 15 minute sessions to helping an anxious patient. Other members of the practice, such as a practice nurse, can be mobilised. Or a counsellor with accredited qualifications can be employed on a sessional basis.

\section{Psychological techniques}

Although many patients respond to the simple measures outlined above, some need drug intervention or more formal psychological therapy. ${ }^{10}$ The range of available techniques is wide and includes the following.

Applied relaxation-The patient is taught how to relax various groups of muscles by alternately tensing and relaxing them." After practising this in a lying or sitting position, he or she moves on to applying this method of reducing anxiety while undertaking daily activities.

Graded exposure-The way that avoidance of a phobic situation perpetuates anxiety and panic is explained to the patient. $\mathrm{He}$ or she is then encouraged to confront the feared objects or situations but in a gradual way, starting with the easiest. The patient stays in the phobic situation until the anxiety subsides.

Assertiveness training-The therapist attempts to broaden the repertoire of the patient's responses in an inhibited interpersonal relationship. A range of methods is used, from exposure in imagination to role playing.

Cognitive therapy-Anxious thinking-that is, attitudes, beliefs, and images-about the external world can instigate or perpetuate anxiety and panic. These are controlled by teaching the patient how to recognise and re-examine anxious thinking so as to uncover different, more constructive, and less anxiety provoking ways of viewing the outside world. ${ }^{12} \mathrm{~A}$ variant of this approach can be applied to panic attacks: the patient is believed to be sensitive to bodily feelings which he or she then misinterprets "catastrophically" as a signal of impending death. ${ }^{13}$ Cognitive therapy aims at changing that misinterpretation.

Anxiety management-This takes elements of some of the other techniques together with help with coping with anxiety, avoiding maladaptive practices, and distraction techniques. The various elements may be used in different combinations at different times during a short course of therapy.

Psychotherapy-This covers a very wide range of approaches from brief focal psychotherapy and more intensive counselling to long term, analytic based therapies, either individual, marital, family, or group. The aims are various but an important one is to uncover the roots of the anxiety and panic.

Psychological treatments are generally effective. About half of patients regain a normal level of functioning, and cognitive therapy is claimed to be the most efficacious. ${ }^{14} \mathrm{By}$ and large, these therapies work best in patients with milder illness and in those whose anxiety is ascribable to clear cut causes.

All these therapies require motivation, time, and commitment on the part of the patient. The practicalities may present local difficulties. Trained clinical psychologists are in short supply nationally, and psychotherapists tend to congregate in urban centres. Some of the techniques can be taught to community psychiatric and practice nurses, and it may be that available clinical psychology resources are best used to supervise other ancillary staff. A particularly urgent role would be to contribute to the training of general practitioners, but it must be recognised that only a minority, perhaps very few, would want to spend time applying these techniques themselves. The expansion of clinical psychology services is urgently needed.
Box 3-Psychological techniques
- Applied relaxation
- Exposure
- Assertiveness training
- Cognitive therapy
- Anxiety management
- Directive counselling
- Non-directive counselling
- Psychotherapies-brief, family, group, psychoanalytic, etc

\section{Drug treatment}

Drug treatment is still common for patients with generalised anxiety disorder and panic disorder with moderate to severe symptoms. Concern over benzodiazepines has led to an exploration of the use of other medications in these conditions, both older drugs such as the $\beta$ blockers and tricyclic antidepressants and newer ones such as the selective serotonin reuptake inhibitors.

The problems with benzodiazepines have been reviewed many times, ${ }^{1516}$ but several points bear repetition. Short term side effects include sedation and impairment of psychomotor and cognitive function, with adverse consequences for everyday activities such as car driving and intellectual pursuits. ${ }^{17}$ Aggressive outbursts may occur. ${ }^{18}$ Longer term memory disturbances may persist, ${ }^{19}$ but the main concerns are about withdrawal.

About a third of long term users develop a clinically important abstinence syndrome, even on gradual taper- 
ing of benzodiazepine. Lorazepam and alprazolam are generally regarded as the most troublesome. About a half of those who develop major withdrawal syndromes fail to stop using tranquillisers permanently. Various stratagems can be used to help withdrawal, ${ }^{15}$ but the most important is to treat any coexistent depression. The prescriber's dilemma is that although most patients can limit a course of benzodiazepine treatment to intermittent use, or no more than a week or two, someperhaps $10 \%$ - cannot and may go on to long term use and become dependent. It is difficult to predict those at risk. This consideration must be set against the advantages of the benzodiazepines-useful and rapid efficacy, few somatic side effects, and safety in overdose. ${ }^{20}$

Drugs other than benzodiazepines include the following:

Buspirone is fairly effective short term but with a slow, progressive onset of action. ${ }^{21}$ It has reduced efficacy in patients with extensive prior benzodiazepine use. Side effects include dizziness, headache, and nausea but sedation is usually minimal. Buspirone does not interact with alcohol, and the potential for dependence and abuse seems minimal.

Box 4-Drug treatments
- Benzodiazepines
- Buspirone
- $\beta$ Blockers
- Tricyclic antidepressants
- Selective serotonin reuptake inhibitors
- Monoamine oxidase inhibitors
- Antipsychotic drugs in low dose
- Antihistamines

$\beta$-Adrenoceptor antagonists have long been used to treat anxiety. They are effective in performance and stress related anxiety but less so in generalised anxiety disorder and panic disorder. ${ }^{22}$ Side effects include tiredness and nightmares, but the drugs produce little sedation and are unlikely to produce dependence or abuse.

Tricyclic antidepressants vary in their apparent efficacy in anxiety disorders, ${ }^{23}{ }^{24}$ but good data support the use of imipramine or clomipramine in panic disorder. ${ }^{25}$ Dosage must be low initially but then needs to rise to the doses typically used to treat depression. The full panoply of side effects may occur, and anxiety may worsen transiently. The tricyclic antidepressants are dangerous in overdose.

Newer antidepressants such as mianserin and lofepramine have not been evaluated in anxiety disorders.

Selective serotonin reuptake inhibitors such as fluvoxamine, fluoxetine, sertraline, and paroxetine have been used to treat anxiety, especially when it is mixed with depression, ${ }^{26}$ but few formal assessments have been reported. Although usually better tolerated than tricyclic antidepressants and much less toxic, selective serotonin reuptake inhibitors are more expensive.

Monoamine oxidase inhibitors are effective in phobic and panic anxiety but may take up to eight weeks to become effective. ${ }^{27}$ Side effects include postural hypotension, oedema, and dietary and drug interactions. Moclobemide, a reversible and selective monoamine oxidase inhibitor, has fewer side effects and minimal dietary restriction ${ }^{28}$; it is currently being evaluated in the treatment of panic disorder.

Antipsychotic drugs in low doses are favoured by some practitioners. However, they induce autonomic symptoms and restlessness, and there is a risk of tardive dyskinesia with chronic use.
Antihistamines have also been used as anxiolytics but are very sedative. There is little evidence of their efficacy.

\section{TREATMENT PLANS}

The use of drugs to treat anxiety and panic must be part of a coherent management plan. Antianxiety drugs suppress the symptoms of anxiety to some extent, sometimes quite effectively, but they do not deal with the root causes of the disorders. When anxiety is anticipatory, clearly associated with an infrequent but unavoidable event such as air travel on holiday, or is so severe as to preclude any other treatment, a short course of treatment with a benzodiazepine may be not only appropriate but essential. However, the patient should be carefully counselled about the need for a tranquilliser, the importance of limiting the course to one or two weeks, and the strategy for discontinuation. Thus, a third week at half dosage to minimise rebound is often advantageous. The patient must be warned about possible impairment of driving skills, judgment, and memory and not to drink alcohol. The treatment should be monitored closely, both for unequivocal efficacy and side effects. Dosage should be cautious and carefully increased after a few days if necessary. Anxiety management should be instituted as the anxiety is controlled. If anxiety levels do not drop adequately, alternative drug therapies must be considered and substituted before benzodiazepine use becomes long term.

If it seems that drug treatments may be needed long term, benzodiazepines should be avoided. Clues as to this come from a careful elicitation of the history of the patient's psychological problems and previous usage of anxiolytics. If depression is present, if the anxiety is chronic, or if panic attacks are disabling the treatment of choice is an antidepressant. Among the tricyclic antidepressants, imipramine or clomipramine seem the best choice. The selective serotonin reuptake inhibitors are relatively untried, and it may be best to keep them in reserve. Buspirone is useful in patients with generalised anxiety disorder, but its efficacy in panic disorder seems minimal.

One or other antidepressant should eventually help control anxiety, especially when it takes the form of panic attacks. The appropriate non-drug measures should be instituted as soon as possible to treat cognitive and behavioural aspects of the disorder. Finally, and this may be in months rather than weeks, the drug treatment can be tapered off. Brief booster courses of psychological treatment are ideal if at all feasible.

\section{Referral to a specialist}

Most patients with generalised anxiety disorder and panic disorder are treated in primary care. Those referred to a psychiatrist are typically the most severely or chronically ill; those with comorbid depression, especially if suicidal; and those with major personality and intractable social problems. The hospital specialist will reassess the patient, attempting to relate him or her to the interpersonal, social, and occupational background. Immediate precipitating causes will be sought, even if at first sight the generalised anxiety disorder or panic disorder seems totally inexplicable. Further physical investigations may be recommended if the features of the illness seem untypical of anxietyfor example, an electroencephalogram if symptoms indicating temporal lobe epilepsy are elicited.

The experienced specialist will always try to exclude the use of alcohol or illicit drugs, particularly of alcohol, and may request the appropriate biochemical tests. Anxiety or panics occurring for the first time in middle aged or elderly people will raise the possi- 
bility of an underlying depression or dementia or an organic cause such as a brain tumour. Psychometric assessment may help if a dementing process is suspected.

Admission to hospital, rather than for special investigations, is not usually necessary. Many patients improve as their environmental stresses are avoided, only to relapse on discharge. Outpatient, or occasionally day patient, status is usually more appropriate. Liaison with the primary care team is essential to maintain a treatment plan and to prevent the occasional patient misusing benzodiazepines or other sedatives. One strategy that is being adopted increasingly is for the psychiatrist to have sessions in a primary care practice, treating patients referred from within that practice suffering from generalised anxiety disorder and panic disorder.

1 Royal College of General Practitioners, Office of Population Censuses and Surveys, and Department of Health and Social Security. Morbid statistics from general practice. Third national study, 1981-82. London: HMSO, 1986.

2 Quality Assurance Project. Treatment outlines for the management of anxiety states. Aus NZ f Psychiatry 1985;19:138-51.

3 Lader $M$, ed. Guidelines for the management of patients with generalised anxiety. Psychiat Bull 1992;6:650-5.

4 American Psychiatric Association. Diagnostic and statistical manual of mental disorders (3rd ed, revised) (DSM-III-R). Washington, DC: APA, 1987.

5 Goldberg D, Huxley P. Common mental disorders: a bio-social model. London: Routledge, 1992 .

6 Bruce MS, Lader M. Caffeine: clinical experimental effects in humans. Hum Psychopharmacol 1986;1:63-82.

7 Tiller JWG, Schweitzer I. Benzodiazepines. Depressants or antidepressants? Drugs 1992;44:165-9.

8 Donnan P, Hutchinson A, Paxton R, Grant B, Firth M. Self-help materials for anxiety: a randomised controlled trial in general practice. $B r \mathcal{F}$ Gen Practice 1990;40:498-501.

9 Jannoun L, Oppenheimer C, Gelder M. A self-help treatment programme for anxiety state patients. Behav Ther 1982;13:103-11.
10 Davis J da R, Gelder M. Long-term management of anxiety states. Int Rev Psychiatry 1991;3:5-17.

11 Raskin M, Bali L, Peeke H. Muscle biofeedback and transcendental meditation: a controlled evaluation of efficacy in the treatment of chronic anxiety. Arch Gen Psychiatry 1980;37:93-7.

12 Durham RC, Turvey AA. Cognitive therapy $v$ behaviour therapy in the treatment of chronic generalised anxiety. Behav Res Ther 1987;25:229-34.

13 Clark DM, Salkovskis PM, Gelder MG, Koehler C, Martin M, Anastasiades P, et al. Tests of a cognitive theory of panic. In: Hand I, Wittchen HV, eds. Panic and phobias: 2. Berlin: Springer-Verlag, 1988:149-58.

14 Durham RC, Allan T. Psychological treatment of generalised anxiety disorder. A review of the clinical significance of results in outcome studies since 1980 . Brf Psychiatry 1993;163:19-26.

15 Hallström C, ed. Benzodiazepine dependence. Oxford: Oxford University Press, 1993.

16 Salzman C. Behavioural side effects of benzodiazepines. In: Kane JM, Lieberman JA, eds. Adverse effects of psychotropic drugs. New York: Guilford Press, 1992:139-52.

17 Curran HV. Benzodiazepines, memory and mood: a review. Psychopharmacology 1991;105:1-8.

18 Dietch JT, Jennings RK. Aggressive dyscontrol in patients treated with benzodiazepines. $₹$ Clin Psychiatry 1988;49:184-7.

19 Ghoneim MM, Mewaldt SP. Benzodiazepines and human memory: a review. Anesthesiology 1990;72:926-38.

20 Serfaty M, Masterton G. Fatal poisonings attributed to benzodiazepines in

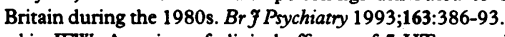

21 Deakin JFW. A review of clinical efficacy of $5-\mathrm{HT}_{1 \mathrm{~A}}$ agonists in anxiety and depression. $\mathcal{F}$ Psychopharmacol 1993;7:283-9.

22 Tyrer P. Current status of $\beta$-blocking drugs in the treatment of anxiety disorders. Drugs 1988;36:773-83.

23 Tyrer P, Seivewright N, Murphy S, Ferguson B, Kingdon D, Barczak P, et al. The Nottingham study of neurotic disorder: comparison of drug and psychological treatments. Lancet 1988 ;ii:235-40.

24 Rickels K, Downing R, Schweizer E, Hassman H. Antidepressants for the treatment of generalized anxiety disorder. Arch Gen Psychiatry 1993;50: 884-95.

25 Cross-National Collaborative Panic Study, Phase Two. Drug treatment of panic disorder. Comparative efficacy of alprazolam, imipramine, and placebo. Br f Psychiatry 1992;160:191-202.

26 Westenberg HGM, den Boer JA. Selective monoamine uptake inhibitors and a serotonin antagonist in the treatment of panic disorder. Psychopharmacol Bull 1989;25:119-23.

27 Sheehan DV, Ballenger J, Jacobson G. Treatment of endogenous anxiety with phobic, hysterical and hypochondrial symptoms. Arch Gen Psychiatry 1980;37:51-9.

28 Fitton A, Faulds D, Goa KL. Moclobemide. A review of its pharmacological properties and therapeutic use in depressive illness. Drugs 1992;43:561-96.

\section{Research Profile}

\section{Developing foresight: an interview with Sir Dai Rees}

\section{Richard Smith}

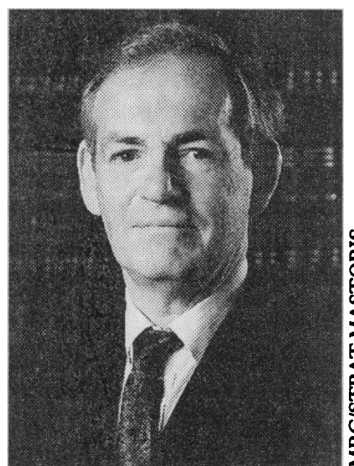

"Foresight is, I think, the most comprehensive and promising method that we've developed to... make sure that we implement and profit from our discoveries in science."

British Medical Journal, London WC1H 9JR Richard Smith, editor want. Britain.
One of the centrepieces of the British government's strategy for science is a process called technology foresight. Sir Dai Rees, chief executive of the MRC, is a member of the steering group charged with developing foresight. Richard Smith asked him about the subject.

\section{Rs: What is technology foresight?}

DR: It's an attempt to consider possible future relations between science and technology and the needs of society and industry. So, for example, in health we know that we will have an aging population and we fear the development of more microorganisms resistant to antibiotics. These are challenges both for health care services and for industry. We look at issues like that alongside information on how science is likely to develop and see whether science might help us with the problems. We can then plan our research activities to make it more likely that we will get the outcomes we

The government is interested because this may be a way of improving the industrial competitiveness of

Rs: Where did the idea come from?

DR: It has a Japanese origin. The whole world looks at the Japanese economic miracle with envy and asks how they did it. There are many examples of them seeing before others what to do with science-for example, with liquid crystal displays, which were discovered in Britain. And technology foresight seems to have been one of the things that allowed the Japanese to be so prescient and forward looking.

The Dutch and the Germans followed, but in the Thatcher years Britain was not interested. She believed that it was no job of government to try to pick winners in science and technology. While we agree we should not pick winners, we do now believe that it makes sense for those who follow social and market trends to speak to those who look to the future of science and technology.

\section{"Technology foresight seems to have been one of the things that allowed the Japanese to be so prescient and forward looking."}

This is yet another method-along with much else like interdisciplinary research centres and programmes linking science and industry - to try to make sure that we implement and profit from our discoveries in science.

Foresight is, I think, the most comprehensive and promising method that we've yet developed to tackle this problem. What we are not yet sure about is whether the value will lie purely in scientists and engineers developing networks with others to look to the future and to foster a common understanding and 